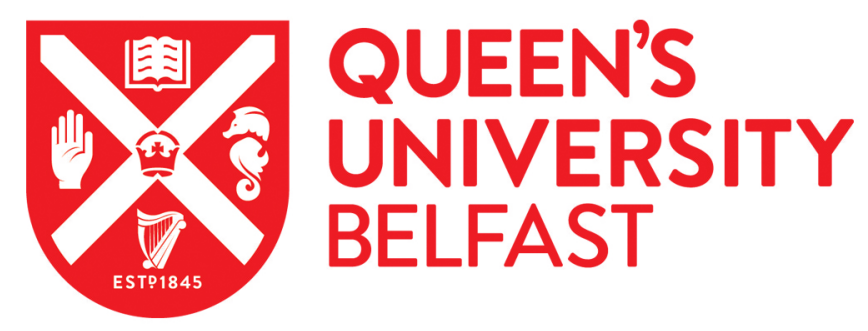

\title{
Power System Steady-State Analysis with Large-Scale Electric Vehicle Integration
}

Zhou, B., Littler, T., Meegahapola, L., \& Zhang, H. (2016). Power System Steady-State Analysis with LargeScale Electric Vehicle Integration. Energy, 115(1), 289-302. https://doi.org/10.1016/j.energy.2016.08.096

\author{
Published in: \\ Energy
}

Document Version:

Peer reviewed version

Queen's University Belfast - Research Portal:

Link to publication record in Queen's University Belfast Research Portal

Publisher rights

(c) Elsevier Ltd. 2016. This manuscript version is made available under the CC-BY-NC-ND 4.0 license

http://creativecommons.org/licenses/by-nc-nd/4.0/

\section{General rights}

Copyright for the publications made accessible via the Queen's University Belfast Research Portal is retained by the author(s) and / or other copyright owners and it is a condition of accessing these publications that users recognise and abide by the legal requirements associated with these rights.

Take down policy

The Research Portal is Queen's institutional repository that provides access to Queen's research output. Every effort has been made to ensure that content in the Research Portal does not infringe any person's rights, or applicable UK laws. If you discover content in the Research Portal that you believe breaches copyright or violates any law, please contact openaccess@qub.ac.uk. 


\section{Power System Steady-State Analysis with Large-Scale Electric Vehicle Integration}

Bowen Zhou* ${ }^{1}$, Tim Littler ${ }^{1}$, Lasantha Meegahapola ${ }^{2}$, Huaguang Zhang ${ }^{3}$

${ }^{1}$ School of Electronics, Electrical Engineering and Computer Science, Queen's University Belfast, Belfast, BT9 5AH, UK

${ }^{2}$ School of Electrical and Computer Engineering, RMIT University, GPO Box 2476, Melbourne, Victoria 3001, Australia

${ }^{3}$ Electric Automation Institute, Northeastern University, Shenyang, 110004, PR China

bzhou02@qub.ac.uk

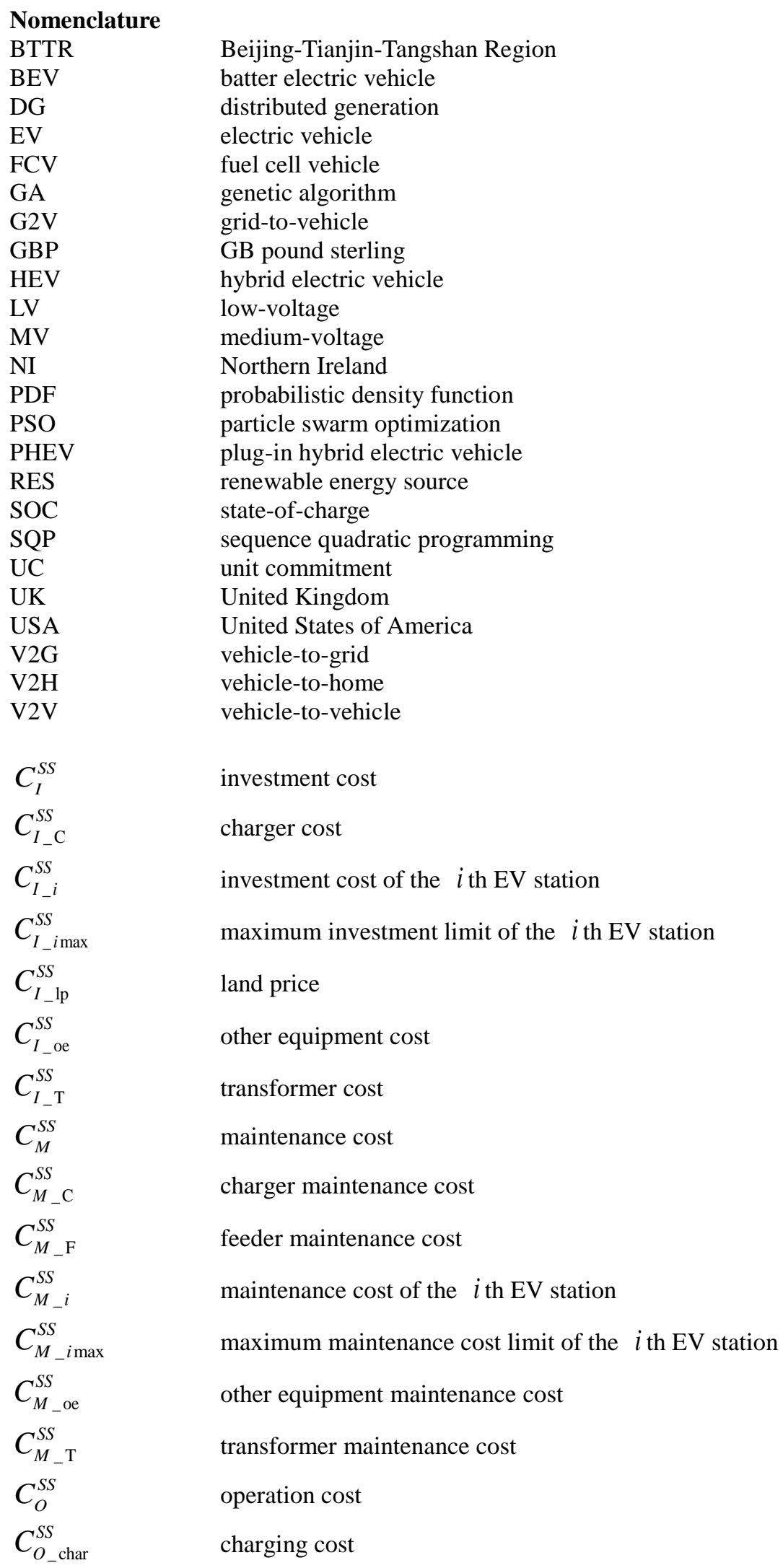


$C_{O_{-} \text {dis }}^{S S}$

$C_{O_{-} \mathrm{hs}}^{S S}$

$C_{O_{-} i}^{S S}$

$C_{O_{-} i \max }^{S S}$

$C_{O_{-} \text {power }}^{S S}$

$C T_{p}$

$d$

$d_{R}$

$E, E^{S S}$

$E_{a}$

$E_{B}$

$E_{c j}$

$E_{c_{-} s e t}$

$E_{d j}$

$E_{k}$

$E_{l}$

$E_{\text {start }}, E_{\text {end }}$

$f(l), g(l)$

$h, h^{S S}$

$I_{\text {line }}(l)$

$K_{P}$

$K_{U}$

$L_{i k}^{S S}$

$L_{k \max }^{S S}$

$M_{\text {char }}, M_{\text {dis }}$

$N$

$N_{a}$

$N_{B}$

$N_{c}$

$N_{\text {char }}$

$N_{d}$

$N_{\text {dis }}$

$N_{F C}$

$N_{H}$

$N_{l}$

$N_{p}$

$N^{S S}$

$N_{\alpha}, N_{\beta}, N_{\gamma}, N_{\phi}$ discharging cost

human service cost

operation cost of the $i$ th EV station

maximum operation cost limit of the $i$ th EV station

power consumption cost of electric devices

charging cycle of charging-only EVs

daily travel distance

maximum range of $\mathrm{EV}$

SOC

available SOC

capacity of EV battery packs

discrete SOC before charging starts from each time interval

setting value of start SOC for charging-only EVs

discrete SOC before discharging starts from each time interval

SOC at start time

SOC at a later time $l$ after $m$ intervals charging and $n$ intervals discharging

start point SOC and end point SOC

decision variables

PDF of initial SOC after one day travel

current of each line at time $l$

power steady-state stability reserve

voltage steady-state stability reserve

distance between the $i$ th EV station and the $k$ th main parking lot

range limit of the $k$ th main parking lot

cost per unit power in the economic calculation and carbon emission reduction amount per unit power in environmental application

total EV number

number of flexible charging EVs

number of BEVs

number of the time intervals of the charging and discharging process

number of EVs at charging

number of discrete time intervals

number of EVs at discharging

number of FCVs

number of PHEVs

total number of transmission lines in the system

number of charging-only EVs

total number of EV stations planned in a specific area

number of flexible EVs under different scenarios 


\begin{tabular}{|c|c|}
\hline$P_{a}(l)$ & charging power of flexible EVs at time $l$ \\
\hline$P_{B d}$ & battery rated discharging power \\
\hline$P_{c}$ & rated charging power \\
\hline$P_{c_{-} \text {total }}$ & total charging power \\
\hline$P_{c \_t o t a l}^{M}$ & total charging cost \\
\hline$P_{\text {char }}$ & charging power \\
\hline$P_{d}$ & rated discharging power \\
\hline$P_{d_{-} \text {total }}$ & total discharging power \\
\hline$P_{c_{-} \text {total }}^{M}$ & total discharging cost \\
\hline$P_{d i s}$ & discharging power \\
\hline$P_{E V}(l)$ & EV charging power at time $l$ \\
\hline$P_{E V}^{M}(l)$ & EV charging cost at time $l$ \\
\hline$P_{E V}^{S S}$ & EV power demand at EV stations \\
\hline$P_{E V_{-} i}^{S S}$ & EV power demand at the $i$ th EV station \\
\hline$P_{F_{-} i \max }^{S S}$ & maximum load limit in feeders \\
\hline$P_{j}$ & discrete charging/discharging power for the $j$ th period \\
\hline$P_{L}(l)$ & gross load power at time $l$ \\
\hline$P_{\max }$ & maximum power of steady-state stability \\
\hline$P_{\max \text { node }}$ & maximum power limit of each node \\
\hline$P_{\text {node }}(l)$ & power of each node at time $l$; \\
\hline$P_{p}(l)$ & charging power of charging-only EVs at time $l$ \\
\hline$P_{R E S}(l)$ & RES generation power at time $l$ \\
\hline$P_{S}$ & sending power from the infinite bus \\
\hline$P_{S}(l)$ & object power at time $l$ \\
\hline $\bar{P}_{S}$ & mean level of the object power \\
\hline$P_{T_{-} i \max }^{S S}$ & maximum load limit in transformers \\
\hline$R_{\text {line }}$ & resistance of each line \\
\hline$(R+j X)_{i k}^{S S}$ & impendence between the $i$ th EV station and the $k$ th main load node \\
\hline$(R+j X)_{k \max }^{S S}$ & maximum impendence limit of the $k$ th main load node \\
\hline$T_{1}, T_{2}$ & setting time for EV charging curve \\
\hline$t_{3}$ & discharging end time \\
\hline$T$ & time interval \\
\hline$T_{a}$ & available time duration \\
\hline$T_{a \min }, T_{a \max }$ & minimum and maximum value for $T_{a}$ \\
\hline$U_{0}$ & actual operating voltage \\
\hline$U_{c r}$ & critical voltage of load buses \\
\hline$x_{n}$ & sign to identify the existence of EVs \\
\hline$y, z$ & objective function \\
\hline
\end{tabular}




$\begin{array}{ll}\alpha, \beta, \gamma, \phi, \varphi & \text { probabilities } \\ \mu & \log _{e} \text { mean in SOC PDF } \\ \sigma & \text { standard deviation in SOC PDF } \\ \eta & \text { transmission loss percentage }\end{array}$

\begin{abstract}
It is projected that the electric vehicle will become a dominant method of transportation within future road infrastructure. Moreover, the electric vehicle is expected to form an additional role in power systems in terms of electrical storage and load balancing. This paper considers the latter role of the electric vehicle and its impact on the steady-state stability of power systems, particularly in the context of large-scale electric vehicle integration. The paper establishes a model framework which examines four major issues: electric vehicle capacity forecasting; optimization of an object function; electric vehicle station siting and sizing; and steady-state stability. A numerical study has been included which uses projected United Kingdom 2020 power system data with results which indicate that the electric vehicle capacity forecasting model proposed in this paper is effective to describe electric vehicle charging and discharging profiles. The proposed model is used to establish criteria for electric vehicle station siting and sizing and to determine steady-state stability using a real model of a small-scale city power system.
\end{abstract}

Key words: capacity forecasting; electric vehicle (EV); siting and sizing; steady-state analysis

\title{
1 Introduction
}

The integration of renewable energy sources (RES) and electric vehicles (EVs) has been promoted significantly due to fossil fuel shortage and environment concerns as well as smart grid. The manufacturing and marketing of EVs has developed significantly in recent decades. It has been estimated that approximately 1.2 million BEVs and 0.35 million PHEVs will be on road in the UK by 2020 [1]. It has also been determined that there will be a total installation of $53.2 \mathrm{GW}$ of RES including planning projects with a total power demand of $51.8 \mathrm{GW}$ in winter-max scenario in the UK by the same year [2]. Similar statistics are apparent in other developed nations. Thus, it can be concluded that conventional generation and extensive integration of RES are required in future power systems to support normal electric demands, such as domestic, commercial and industrial loads, as well as stochastic loads, especially EVs.

Traditional power system analysis includes developing models of components, network calculations, power flow solutions, fault analysis and stability analysis. Analyses operate mainly in the time domain and involve steady-state analysis, transient state analysis and dynamic state analysis - where steady-state analysis is the basis of the other two [3]. This paper focuses on future power system with large-scale EV integration and examines pertinent technical issues in steady-state analysis, which are regarded as fundamental to both transient and dynamic state analysis. Such issues include EV capacity forecasting, development of an optimization object function, EV station siting and sizing and steady-state stability.

There have been numerous publications to date which consider EV capacity forecasting. Liu et al [4] discuss the opportunities and challenges of Vehicle-to-Home (V2H), Vehicle-to-Vehicle (V2V), and Vehicle-to-Grid (V2G) technologies. An EV aggregator model and the optimal EV demand calculation flowchart based on the Genetic Algorithm (GA) are introduced. EVs are assumed to be fully charged or discharged in the examples. Shaaban et al [5] and Liu et al [6] use Monte Carlo simulation for normally distributed virtual trips and EV initial state-of-charge (SOC). The trip model [5] is applied in the EV energy consumption model. Rolink and Rehtanz [7] use the homogeneous semi-Markov process to determine the probability of EV resting at a defined location and at a given time: the total EV capacity is calculated based on this probability and the rated charging power and EV numbers. Other methods, such as hierarchical decomposition [8], multi-agent [9], and normal distribution [10, 11] have also been used to describe EV probabilistic parameters. Hierarchical decomposition [8] consists of two levels: the upper-level minimizes the total cost of system operation by providing dispatch orders to generators and EVs; the lower-level manages individual EV charging using dispatch orders from the upper-level. Karfopoulos and Hatziargyriou [9] propose a distributed, multi-agent EV charging control method based on the Nash Certainty Equivalence Principle for controlled charging of large-scale EVs: however, the validity and feasibility for discharging is not discussed. As stated in [10], a normal distribution is the simplest way to express one of the probabilistic characteristics of EV plug-in time. However, this may be not practical and a log-normal distribution can be used instead. In [11], electricity market issues and EV capacity are considered as V2G reserve to participate in reserve market trading. In the above publications, EV data is typically derived from simulation studies. However, in other papers real transportation statistical data has been used, since it is more accurate in describing driver travel behavior. In particular, data from the Beijing-Tianjin-Tangshan Region (BTTR) in China is used in [12]; data from the UK national travel survey is used in [13]. Real transportation data from Sweden [14], Japan [15], and the Netherlands [16] have also been introduced in recent publications. Madzharov et al [14] consider Swedish EV data which focuses on EV participation on the generation side for unit commitment (UC). Wang et al [15] use Tokyo 2030 EV data to analyze EV economic and environmental performance under different generation mix, smart charging and real-time pricing. Bellekom et al [16] focus on EV support for wind power where the predicted Dutch 2020 provision is specified.

Papers [11] and [12] have not considered time-domain variation and have only focused on peripheral calculations for power and energy balancing. However, inclusion of time-domain variation is essential to develop accurate prediction of charging and discharging capacity, which can then be used directly to determine applications to load levelling [13, 17] and RES support [18]. Existing work on EV capacity forecasting has not systematically addressed all uncertainties in this process. Furthermore, in publications to date, EV charging (Grid-to-Vehicle, G2V) and discharging (V2G) capacity models usually adopt a continuous calculation, meaning the charging process does not come to the end until the battery is fully 
charged or the discharging process does not stop until the SOC reaches a certain level. This type of charging or discharging strategy cannot meet the requirements for practical daily travel and commute for EV owners [19], who require non-continuous/alternate charging or discharging. Thus, a flexible EV capacity forecasting model needs to be developed. Moreover, while being user flexible, this model should also be adaptable for different types of applications such as load levelling, tie-line regulation, RES support, and cost-benefit solutions.

It is feasible to consider EVs in power system dispatch, however inappropriate siting and sizing of charging/discharging stations may render negative impacts on EV development and investment [20-22]. EV station siting and sizing requires combined and accurate assessment of power system capacity, geographic information, traffic routes and layout and cost minimization. Liu et al [20] developed an optimal planning method for location and planning for EV charging stations in distribution systems. However, the total EV number considered was limited and the siting and sizing results are for distribution grids with voltage levels $<11 \mathrm{kV}$. Moradijoz et al [21] present a multi-objective approach to determine optimal site and size of EV stations which considers a V2G mode as distributed generation (DG) in power distribution networks: reliability and power loss issues are included in the proposed approach; however, real geographic information or traffic layout has not been considered. Jia et al [22] introduced an optimization process for sizing and siting of EV charging stations based on the structure of the road network and graph theory. However, such stations are installed along roads only and a more appropriate and optimal siting and sizing approach for large-scale EV integration needs consideration.

This paper considers future power systems in terms of the impact of large-scale EV integration on steady-state stability and directly related issues. The approach adopted in this paper and contributions of this work are summarized as follows:

1) An EV capacity forecasting model is developed to determine charging and discharging capacity. Nine particular uncertainties in three different categories are considered in this model. EVs are divided as charging-only EVs and flexible EVs. Here, flexibility means that when an EV is plugged-in within a specific time period, charging and/or discharging process starts continuously or occurs alternately between different time intervals. The proposed model is suitable for different objects of optimization. Hence using the proposed model the number of EVs during a certain time interval, undergoing charging or discharging (at certain power levels and with probabilistic initial SOC) can be obtained.

2) A three-step EV station optimal siting and sizing approach is proposed. Six factors with respect to power system capacity, geographic information, traffic layout, and cost minimization are considered. The approach is designed for large-scale EV integration and the outcomes determine EV station sizes and station connection nodes at grid level. An optimization object developed as part of this approach assesses total cost.

By applying the proposed capacity forecasting model and the sizing and siting approach, the power flow distribution of an EV integrated power system can be obtained. The paper presents timely academic and technical contributions to knowledge in EV integration to manage power system dispatch and capacity in selected time slots at any network location node. While the model framework provides access to the injection currents of EV blocks for power network analysis, which is critical for load and power flow studies, the approach effectively decouples the stochastic and intermittent behaviour of EVs (in time, location and energy capacity/requirement) from the energy system to provide a transparent method of demand-response (DR) management to minimise the impact of large-scale integration of EVs.

This paper is organized as follows: Section 2 provides the problem description of power system steady-state analysis with large-scale EV integration; Section 3 develops a general model for EV capacity forecasting considering nine uncertainties; Section 4 discusses the applications of the proposed model in three categories; Section 5 proposes the EV station siting and sizing approach; and Section 6 introduces indices for evaluation of steady-state stability. Numerical case studies are presented in Section 7 using an example micro-grid and predicted Northern Ireland (NI) 2020 statistical data. Finally, Section 8 concludes the work reported in this paper.

\section{Problem description}

Traditional power system steady-state analysis includes modelling, power flow solutions, active power and frequency regulation, reactive power and voltage control, and steady-state stability. With large-scale EV provision and integration, further issues such as EV capacity forecasting, EV station siting and sizing, and coordination with RES should be taken into consideration. Fig. 1 shows the problem description of this paper.

As a comparatively new component in power system analysis, EV charging and discharging capacity forecast modelling is a necessary element for appropriate EV integration. A model should be proposed at first: EV charging and discharging power profile in time domain is usually called the optimal profile or scheduled profile, which is obtained from optimizations Thus, the proposed model should be combined with optimal objects including load levelling, tie-line regulation, and RES support. Thereafter, the time and magnitude issues of EV stochastic and intermittent characteristics are addressed considered.

In terms of power network connections, EV stations which host large-scale EV integration are destined for connection at 11 or $33 \mathrm{kV}$ on distribution level buses [2,23]. With voltage levels $<11 \mathrm{kV}$, EV connections are typically at domestic and household voltage level [2, 24], for single EV connection. The siting and sizing of EV stations considers the location issue of EV characteristics. Therefore, an EV power requirement at a certain time interval at a certain location can be obtained, indicating that the power flow solution of large-scale EV integrated power systems can be achieved.

Steady-state stability is used in power system planning to determine the limits of transmission power (in steady-state). With EV integration, steady-state stability is used to limit the maximum EV charging and discharging power. In steady-state stability, two indices, power steady-state stability reserve and voltage steady-state stability reserve, are usually used to describe the steady-state stability margin.

In this paper, active power/frequency regulation and reactive power/voltage control are not discussed since they are more related to power system operation rather than stability. 
To accomplish steady-state analysis with large-scale EV integration, all of the above issues should be clearly specified since a steady-state analysis with large-scale EV integration is a multi-object, multi-constraint, high-dimensional, nonlinear, and discrete optimization problem.

\section{$3 \mathrm{EV}$ capacity forecasting model}

EV capacity forecasting provides an accurate time-domain profile for scheduled charging and discharging. Due to stochastic and intermittent usage and EV user behavior, there are uncertainties in charging and discharging forecasting. In this paper, several assumptions are considered for discussion of such uncertainties, as follows:

1) EV battery lifespan is assumed sufficient for non-continuous charging and discharging based on recent advances in battery technologies [25-28], which are subsequently discussed in detail;

2) Step change is considered between each time interval for charge-to-discharge mode, and vice versa;

3) Future grid scenarios are considered for the optimal charging and discharging strategy.

Most current EV batteries are guaranteed for an 8-10 year lifespan [25], which means that a battery pack is expected to retain $70-80 \%$ of its capacity after this period. If daily charging and discharging is assumed, the lifespan is anticipated to be at least 3000 cycles. Moreover, a typical EV battery cell specification [26] shows that capacity can exceed $75 \%$ after 3000 cycles. According to state-of-health $(\mathrm{SOH})$ battery studies [27-28], a cycle range within 0.4-0.7 SOC (or a wider range of 0.3-0.8 SOC) is considered to have a limited influence on battery lifespan, making non-continuous charging or alternate charging/discharging (charging/power consumption) possible.

In this paper, nine uncertainties for capacity forecasting, in relation to power system integration are discussed in detail. These uncertainties are categorized as: deterministic, probabilistic and structural.

\subsection{Deterministic uncertainties}

Five deterministic uncertainties are introduced in this section. They refer to parameters that can be determined from statistics or default parameters. In this category, four parameters are from defaults and the type parameter is from statistics.

\section{1) Types}

EVs usually refer to battery electric vehicles (BEVs), plug-in hybrid electric vehicles (PHEVs) and fuel cell vehicles (FCVs). Assuming $N_{B}, \quad N_{H}$, and $N_{F C}$ are the BEV, PHEV, and FCV numbers, respectively, the total EV number is $N=N_{B}+N_{H}+N_{F C}$

\section{2) EV battery size}

The battery size $E_{B}$ varies significantly for different types of EVs. BEVs usually have a larger battery pack than PHEVs. In Europe, it is recommended that the battery size for a BEV is in the range of 20-30 kWh and for a PHEV, 5-15 kWh [29].

\section{3) Power levels}

Equation (2) describes a typical charging process. The charging process is initially constant with a power level as $P_{r}$. When the charging time or SOC extents some value (for example $T_{1}$ as the setting time), constant voltage charging starts until full charged. Typical charging levels are available in [30-32], which present the USA standard [30], the European standard [31], and the European standard for the UK and Ireland [32].

$$
P_{c}(t)= \begin{cases}P_{r} & 0<t \leq T_{1} \\ P_{r} \frac{\left(T_{2}-t\right)}{\left(T_{2}-T_{1}\right)} & T_{1} \leq t \leq T_{2}\end{cases}
$$

For discharging, there is no well-known standard or engineering practice due to limited V2G applications to date. Currently, there are two ways for EV discharging: firstly, charging is the opposite of discharging; secondly, both charging and discharging are determined by the battery specification. In this paper, the first approach has been adopted in the following case studies.

By considering the charging level and battery constraints, the discharging level is,

$$
P_{r d} \leq \min \left\{P_{r}, P_{B d}\right\}
$$

where $P_{B d}$ refers to the rated power for battery discharging.

\section{4) Time duration availability}

The EV charging and/or discharging period is usually shorter than the parking (connected) period. This longer period is regarded as the time duration availability $T_{a}$. Usually $T_{a}$ will be $<24$ hours, meaning that a charging and/or discharging cycle is counted once a day. However, in some cases if EVs are not supposed to be used within a certain period, $T_{a}$ could be $>24$ hours. Therefore the maximum and minimum value for $T_{a}$ can be determined by user behavior and system dispatch,

$T_{a \min } \leq T_{a} \leq T_{a \max }$

where $T_{a \min }$ and $T_{a \max }$ are the minimum and maximum value for $T_{a}$.

\section{5) Discrete accuracy}

In practice, the EV power is continuous and it is difficult for numerical calculation. As a consequence, the power is divided into separate values for discrete time intervals. In this paper, hours or half-hours are set for steady-state analysis. The separate power $P_{j}$ for the $j$ th period is 
$P_{j}=\int_{(j-1) T}^{j T} P(t) / T d t, \quad 1 \leq j \leq N_{c}, \quad T=24 / N_{d}$

$N_{c}=\left[t_{2}\right] \quad$ round up to nearest hour for charging

$N_{c}=\left[t_{3}\right] \quad$ round up to nearest hour for discharging

where $N_{d}$ is the time period number within 24 hours. It defines the time interval $T . N_{c}$ is the time period number in the charging and/or discharging process; $t_{3}$ is the discharging end time.

\subsection{Probabilistic uncertainties}

Three uncertainties are introduced in this section. Probabilistic uncertainties refer to the parameters which can be described by a probability distribution function (PDF).

\section{6) Human interaction}

The initial SOC and the daily travel distance are usually used to describe the uncertainty of human interaction in EV usage. [33]. The initial SOC is expressed as $E=1-d / d_{R}$ with a linear assumption. $d$ and $d_{R}$ are the average and maximum daily travel distance, respectively. $d$ is obtained from historic statistics.

Therefore the PDF of battery SOC after one day travel is [10], [15]

$$
h(E ; \mu, \sigma)=\frac{1}{d_{R}(1-E) \sqrt{2 \pi} \sigma} \times e^{-\left[\ln (1-E)+\ln \left(d_{R}\right)-\mu\right]^{2} /\left(2 \sigma^{2}\right)}
$$

$0<E<1$

where $\mu$ and $\sigma$ are the $\log _{e}$ mean and the standard deviation, respectively.

\section{7) Discharge availability}

The discharge availability refers to the customer setting for battery Depth-of-Discharge (DOD). The start SOC and end SOC determine the setting of this uncertainty. Thus,

$E_{a} \leq E_{\text {start }}-E_{\text {end }}$

$P_{d}=\left\{\begin{array}{cc}P_{r d} & 0<t \leq t_{3} \\ 0 & t>t_{3}\end{array}\right.$

where $E_{\text {start }}$ and $E_{\text {end }}$ are the start SOC and end SOC.

\section{8) EV power capacity}

Since not every EV gets charged or discharged daily, these EVs typically charge when the SOC is low and they do not participate in discharging. Such EVs are regarded as charging-only EVs. The other EVs, which may charge and/or discharge daily, are regarded as flexible EVs. It is assumed that there are $N_{p}$ charging-only EVs and $N_{a}$ flexible EVs, and $N_{p}+N_{a}=N$. The cycle of charging-only EVs is $C T_{p}$.

- Charging-only EV

If the SOC and the beginning time are independent, the probability of EV beginning charge at time $k$, and charging at the later time $l$ with $P_{c j}$ power is

$$
\begin{aligned}
& \varphi\left(P_{c j}, l\right)=\sum_{k=1}^{l} f(k) h\left(E_{c j}-\sum_{i=1}^{m} E_{c i}\right) \\
& N_{c} \leq l \leq N_{d}, m=l-k<j \\
& E_{k} \leq E_{c_{-} \text {set }}
\end{aligned}
$$

where $h\left(E_{j}-\sum_{i=1}^{m} E_{c i}\right)$ is the probability of the initial SOC; $f(k)$ is the probability that charging commencing at time $k$; $E_{k}$ is the SOC at beginning time and $E_{c_{-} s e t}$ is the start SOC setting.

The power of charging-only EVs at time $l$ is given as,

$P_{p}(l)=N_{p} \sum_{j=1}^{N_{c}} P_{c j} \varphi\left(P_{c j}, l\right)$

\section{- $\quad$ Flexible EV}

Assuming the flexible charging and discharging begins at time $k$, after $m$ intervals charging and $n$ intervals discharging, the SOC at a later time $l$ is,

$$
\begin{aligned}
& E_{l}=E_{k}+\sum_{i=1}^{m} E_{c i}-\sum_{i=1}^{n} E_{d i} \\
& 0 \leq m, n<T_{a}, N_{c}<l<T_{a} \\
& m+n<l-k<j
\end{aligned}
$$

Here, charging and discharging are supposed to be continuous or taken in turns. The charging and discharging scenarios are shown in Table 1.

Take into account (10), the probabilities for the four scenarios are: 


$$
\left\{\begin{array}{l}
\alpha\left(P_{c j}, l\right)=\sum_{k=1}^{l} f(k) h\left(E_{c j}-\left(\sum_{i=1}^{m} E_{c i}-\sum_{i=1}^{n} E_{d i}\right)\right) \\
\beta\left(P_{d j}, l\right)=\sum_{k=1}^{l} f(k) h\left(E_{d j}-\left(\sum_{i=1}^{m} E_{c i}-\sum_{i=1}^{n} E_{d i}\right)\right) \\
\gamma\left(P_{c j}, l\right)=\sum_{k=1}^{l} g(k) h\left(E_{c j}-\left(\sum_{i=1}^{m} E_{c i}-\sum_{i=1}^{n} E_{d i}\right)\right) \\
\phi\left(P_{d j}, l\right)=\sum_{k=1}^{l} g(k) h\left(E_{d j}-\left(\sum_{i=1}^{m} E_{c i}-\sum_{i=1}^{n} E_{d i}\right)\right)
\end{array}\right.
$$

where $g(k)$ is the probability that a discharging begins at time $k$. When $m, n=0$, EV keeps discharging or charging within the begin time $k$ and later time $l$, or the charging or discharging just begins at time $l$.

If the SOC, the beginning time, and the EV number are independent, and the discharging process is considered as a negative charging process, the power demand of flexible EVs at time $l$ can be expressed as

$P_{a}(l)=N_{\alpha} \sum_{j=1}^{N_{c}} P_{c j} \alpha\left(P_{c j}, l\right)-N_{\beta} \sum_{j=1}^{N_{c}} P_{d j} \beta\left(P_{d j}, l\right)$

$+N_{\gamma} \sum_{j=1}^{N_{c}} P_{c j} \gamma\left(P_{c j}, l\right)-N_{\phi} \sum_{j=1}^{N_{c}} P_{d j} \phi\left(P_{d j}, l\right)$

$N_{\alpha}+N_{\beta}+N_{\gamma}+N_{\phi}=N_{a}$

The EV power capacity at time $l$ is

$P_{E V}(l)=P_{p}(l) / C T_{p}+P_{a}(l)$

\subsection{Structural uncertainties}

The only one structural uncertainty refers to the influence from the external power systems at the EV connecting node, for example, the residential load.

\section{9) Residential load}

It is assumed that the conventional distribution grid is closest to the point of consumption. Therefore, EV charging will increase the total load. In V2G mode, feeders in the distribution grid will be subject to reverse-direction current injecting onto the grid. Two major unknowns occur in residential loads: 1) whether or not there is injection current (with or without EV discharging at this node); and 2) the magnitude of injection current (EV numbers at discharging status). This uncertainty is very important to power flow calculation and the SmartPark siting and sizing.

Equation (1)-(13) presented above therefore describe a general model of EV flexible charging and discharging capacity forecasting. In this model, the stochastic nature of EVs is considered by inclusion of the initial SOC and the power level at each time interval. The numbers of EVs in each time interval cannot be obtained directly from this model. However they can be calculated by optimal functions which are discussed in next section.

\section{Application of EV capacity forecasting model}

An EV charging and discharging profile cannot be obtained directly from the model, but is calculated by optimization using a different approach. For simplicity, the above EV capacity forecasting procedure can be derived as follows,

$P_{c_{-} \text {total }}(l)=N_{\text {char }} \sum P_{\text {char }} f(l) h$

$P_{d_{\text {_total }}}(l)=N_{\text {dis }} \sum P_{\text {dis }} g(l) h$

$P_{E V}(l)=P_{c_{-} \text {total }}(l)-P_{d_{-} \text {total }}(l)$

where $P_{c_{-} \text {total }}$ is the total charging power of $N_{\text {char }}$ EVs charging at time $l$ with power $P_{\text {char }} ; P_{d_{-} \text {total }}$ is the total discharging power of $N_{d i s}$ EVs discharging at time $l$ with power $P_{d i s} ; h$ is the PDF of SOC; $f(l)$ and $g(l)$ are EV percentages that begin charging and discharging at time $l$; and $P_{E V}(l)$ is the total EV power demand at time $l$.

Applications of the model proposed in Section 3 can be categorized into three categories: technical, economic, and environmental. Technical applications include load levelling, RES support, tie-line regulation and load loss minimization. Economic applications are mainly cost-benefit calculation and environmental applications are attributed to carbon dioxide emission reductions.

\subsection{Technical Applications}

In load levelling and tie-line regulation, by taking into consideration a flat load profile, a typical optimization function is obtained as follows, 


$$
\begin{aligned}
& P_{S}(l)=P_{E V}(l)+P_{L}(l) \\
& \min z=\frac{1}{N_{d}} \sum_{l=1}^{N_{d}}\left(P_{S}(l)-\bar{P}_{S}\right)^{2} \\
& =\frac{1}{N_{d}} \sum_{l=1}^{N_{d}}\left(P_{S}(l)^{2}-2 P_{S}(l) \bar{P}_{S}+\bar{P}_{S}^{2}\right) \\
& =\frac{1}{N_{d}} \sum_{l=1}^{N_{d}} P_{S}(l)^{2}-\frac{2 \bar{P}_{S}}{N_{d}} \sum_{l=1}^{N_{d}} P_{S}(l)+\bar{P}_{S}^{2} \\
& =\frac{1}{N_{d}} \sum_{l=1}^{N_{d}} P_{S}(l)^{2}-\bar{P}_{S}^{2} \\
& \min z=\sum_{l=1}^{N_{d}} P_{S}(l)^{2} \\
& \text { s.t. }\left\{\begin{array}{l}
\sum f(l)+\sum g(l)=1 \\
f(l) \geq 0, g(l) \geq 0, \forall t \in\left[1, N_{d}\right]
\end{array}\right.
\end{aligned}
$$

where $P_{S}(l)$ is the net demand or net tie-line transferred power with EV at time $l ; P_{L}(l)$ is the demand or tie-line transferred power without EVs at time $l ; \bar{P}_{S}$ is the average load demand or tie-line transferred power and $\bar{P}_{S}=\sum_{l=1}^{N_{d}}\left(P_{E V}(l)+P_{L}(l)\right) / N_{d} ; \quad z$ is the objective function and $f(l)$ and $g(l)$ are the decision variables.

In RES support, if the RES is assumed as a negative load, then optimization function can be obtained as,

$P_{S}(l)=P_{E V}(l)+P_{L}(l)-P_{R E S}(l)$

$\min z=\frac{1}{N_{d}} \sum_{l=1}^{N_{d}}\left(P_{S}(l)-\bar{P}_{S}\right)^{2}$

$\min z=\sum_{l=1}^{N_{d}} P_{S}(l)^{2}$

s.t. $\left\{\begin{array}{l}\sum f(l)+\sum g(l)=1 \\ f(l) \geq 0, g(l) \geq 0, \forall t \in\left[1, N_{d}\right]\end{array}\right.$

where $P_{R E S}(l)$ is the RES generation power at time $l$ and $P_{L}(l)$ is the gross demand without EVs at time $l$. By considering residential load uncertainty and system configuration, $P_{E V}(l), P_{L}(l)$, and $P_{R E S}(l)$ are obtained by power flow calculation.

\subsection{Economic and Environmental Applications}

In economic and environmental application, several modifications need to be clarified in (14) such that,

$P_{c_{-} \text {total }}^{M}(l)=M_{\text {char }} N_{\text {char }} \sum P_{\text {char }} f(l) h$

$P_{d_{\text {total }}}^{M}(l)=M_{\text {dis }} N_{\text {dis }} \sum P_{\text {dis }} g(l) h$

$P_{E V}^{M}(l)=P_{c_{-} \text {total }}^{M}(l)-P_{d_{-} \text {total }}^{M}(l)$

where $M_{\text {char }}$ and $M_{\text {dis }}$ are the cost per unit power in economic calculation and carbon dioxide emission reduction amount per unit power in environmental applications. In economic calculations, the minus symbol in the third equation means that the discharging process is regarded as a benefit. In environmental calculations, the third equation should be modified as $P_{E V}^{M}(l)=P_{c_{-} \text {total }}^{M}(l)+P_{d_{-} \text {total }}^{M}(l)$, since it is assumed that both charging and discharging limit carbon dioxide emission reduction due to RES acting as the dominant source for battery charging. Thus, the optimization function can be obtained as, $\min z=\sum_{l=1}^{N_{d}} P_{E V}^{M}(l)^{2}$

s.t. $\left\{\begin{array}{l}\sum f(l)+\sum g(l)=1 \\ f(l) \geq 0, g(l) \geq 0, \forall t \in\left[1, N_{d}\right]\end{array}\right.$

where operation cost and investment cost are neglected because they are constant.

As a brief conclusion, based on the proposed EV capacity forecasting model, applications in different domains can be simplified using the same quadratic programming optimization, 
$\min z=\sum_{l=1}^{N_{d}} P(l)^{2}$

s.t.f $(l), g(l)$

where $z$ is the objective function; $f(l)$ and $g(l)$ are the decision variables. This function can be solved by many optimization algorithms such as Sequence Quadratic Programming (SQP) [10], [15], [35] and meta-heuristic algorithms including Genetic Algorithm (GA) [34, 36] and Particle Swarm Optimization (PSO) [34, 37]. In this paper, SQP is used in solving above problems in MATLAB.

\subsection{Transmission losses}

In power system analysis, there are two basic ways to consider the transmission losses. The first approach considers losses as a quadratic expression [34]. This expression is dependent on the system output and the coefficients related to the system configuration. This expression is usually introduced as an added term of the original objective function or a second objective, which makes the original problem one which requires multi-objective optimization. Also, since loss is calculated by power flow calculation at different operating modes, dynamic programming is required [35] to obtain the losses iteratively every time interval. The other approach is based on engineering heuristics and experience [18]. In practice, the transmission loss is broadly considered as typically $7 \%$ of the total output (or total demand), however inclusion of this loss (for analysis), though of minimal magnitude, usually renders the problem more complex. In this paper, RES support is selected as an example to demonstrate the inclusion of transmission losses.

If the practical method is introduced, [16] is modified as follows:

$$
\begin{aligned}
& P_{S}(l)=P_{E V}(l)+P_{L}(l)-P_{R E S}(l) *(1-\eta) \\
& \min z=\frac{1}{N_{d}} \sum_{l=1}^{N_{d}}\left(P_{S}(l)-\bar{P}_{S}\right)^{2} \\
& \min z=\sum_{l=1}^{N_{d}} P_{S}(l)^{2} \\
& \text { s.t. }\left\{\begin{array}{l}
\sum f(l)+\sum g(l)=1 \\
f(l) \geq 0, g(l) \geq 0, \forall t \in\left[1, N_{d}\right]
\end{array}\right.
\end{aligned}
$$

where, $\eta$ is the engineering practical value for transmission losses. A typical value is $7 \%$.

A typical quadratic expression for transmission losses is shown in (21).

$$
\begin{aligned}
& \min y=\sum_{l}^{N_{d}} \sum_{\text {line }}^{N_{l}} R_{\text {line }} I_{\text {line }}^{2}(l) \\
& \text { s.t. }\left\{\begin{array}{l}
\forall l, \forall \text { node }: 0 \leq P_{\text {node }}(l) \leq P_{\max } \\
\forall \text { node }: \sum_{l}^{N_{d}} P_{\text {node }}(l) \cdot \frac{24}{N_{d}} \cdot x_{n}=E_{B} \\
x_{n} \in\{0,1\}
\end{array}\right.
\end{aligned}
$$

where, $N_{l}$ is the total number of transmission lines in the system; $R_{\text {line }}$ is the resistance of each line; $I_{\text {line }}(l)$ is the current of each line at time $l ; P_{n o d e}(l)$ is the power of each node at time $l ; P_{\max \text { node }}$ is the maximum power limit of each node; $x_{n}$ is the sign to identify the existence of EVs.

Combining (16) and (21), a full expression of EV application for RES support considering transmission losses can be obtained. Since a practical method is appropriate for large-scale systems while the quadratic method is more suitable for small systems such as micro-grid, the detailed objective function should be identified according to a real system configuration which is discussed in the subsequent case studies.

\section{EV station siting and sizing}

The basis of EV station siting and sizing is that electric vehicle transportation is considered as "power and energy" transportation. The procedure has two issues, allocation and quantification. Thus, a three-step procedure is proposed.

There are several assumptions in EV siting and sizing:

1) Siting and sizing is designed for large-scale EV clusters, for example car parking lots;

2) EVs are assumed to have a static status, meaning that locations are assumed to mainly remain the same for at least one time interval;

3) Half-day travel distance is roughly considered for SOC estimation.

\subsection{Step I: Preliminary siting}

EV station siting is not only an electrical problem, but also poses civil and economic challenges. A series of factors should be taken into account as follows:

\section{1) Main parking area}

EV owners prefer charging at a fixed location, such as home or work place. The connection of domestic EV charging is usually on a residential low-voltage network. Thus, EV station should be close to main office, work or commercial areas, as 
described in (22),

$0 \leq L_{i k}^{S S} \leq L_{k \max }^{S S}$

$0 \leq i \leq N^{S S}$

where $L_{i j}^{S S}$ refers to the distance between the $i$ th EV station and the $k$ th main parking lot; $L_{k \max }^{S S}$ is the range limit of the $k$ th main parking lot; and $N^{S S}$ is the total number of EV stations planned in a specific area. Here, road geographic information is not included but is estimated in EV power demand estimation.

\section{2) Main load node}

EV stations should be close to the main load area to sufficiently participate in load levelling and emergency power supply, for example. In electrical network analysis, this means the electrical distance between the EV station and load node is reduced as far as possible. Thus,

$0 \leq(R+j X)_{i k}^{S S} \leq(R+j X)_{k \max }^{S S}$

$0 \leq i \leq N^{S S}$

where $(R+j X)_{i k}^{S S}$ refers to the impedance between the $i$ th EV station and the $k$ th main load node and $(R+j X)_{k \max }^{S S}$ is the maximum impedance limit of the $k$ th main load node.

\section{3) Investment cost}

The investment cost $C_{I}^{S S}$ such as land price $C_{I_{-} \mathrm{lp}}^{S S}$, charger cost $C_{I_{-} \mathrm{C}}^{S S}$, transformer $\operatorname{cost} C_{I_{-} \mathrm{T}}^{S S}$ and other equipment cost $C_{I_{-} \mathrm{oe}}^{S S}$ in EV station construction should also be considered,

$C_{I_{-} i \mathrm{p}}^{S S}+C_{I_{-} i \mathrm{C}}^{S S}+C_{I_{-} i \mathrm{~T}}^{S S}+C_{I_{-} i \mathrm{oe}}^{S S}=C_{I_{-} i}^{S S} \leq C_{I_{-} i \max }^{S S}$

where $C_{I_{-} i \max }^{S S}$ is the maximum investment limit of the $i$ th EV station.

Taking into account the above three factors, a number of candidate EV stations can be determined.

\subsection{Step II: Preliminary sizing}

4) EV power demand

According to assumption 3), the PDF of battery SOC at EV station is

$h^{S S}\left(E^{S S} ; \mu, \sigma\right)=\frac{1}{d_{R}\left(1-E^{S S}\right) \sqrt{2 \pi} \sigma} \times e^{-\left[\ln \left(1-E^{S S}\right)+\ln \left(d_{R}\right)-\mu\right]^{2} /\left(2 \sigma^{2}\right)^{2}}$

$0<E^{S S}<1$

Eq. (25) is similar to (6). The only difference is that the SOC is estimated as $E^{S S}=1-d / 2 d_{R}$. Thus, (1)-(5), (7)-(13) and (25) describe the EV power demand at EV stations $P_{E V}^{S S}$. It should also be noted that in different areas the travel patterns are different. Thus, $\mu$ and $\sigma$ will be different due to different preliminary locations. In this paper, different numbers of $\mu$ and $\sigma$ in different areas are neglected due to limited statistical data.

\section{5) Infrastructure limit}

Installation of EV stations poses particular challenges in local infrastructure. Three options are usually adopted: remain-constant, expansion, and new construction. Expansion and new construction requires investment. However, all of these three options should consider the electrical specification of local lines/feeders and transformers,

$\left\{\begin{array}{l}P_{E V_{-} i}^{S S} \leq P_{T_{-} i \max }^{S S} \\ P_{E V_{-i}}^{S S} \leq P_{F_{-} i \max }^{S S}\end{array}\right.$

$\left\{\begin{array}{l}P_{E V_{-} i}^{S S}+P_{L_{-} i} \leq P_{T_{-} i \max }^{S S} \\ P_{E V_{-} i}^{S S}+P_{L_{-} i} \leq P_{F_{-} i \max }^{S S}\end{array}\right.$

where $P_{E V_{-} i}^{S S}$ is the EV power demand at the $i$ th EV station; $P_{T_{-} i \max }^{S S}$ and $P_{F_{-} i \max }^{S S}$ are the maximum load limit in transformers and feeders respectively; and $P_{L_{-} i}$ is the residential or commercial load at the $i$ th load node. Here, (26) describes new construction constraints, meaning that the transformers and feeders are independent. Eq. (27) describes the remain-constant and expansion constraints, meaning that EV demand is integrated with local loads.

6) Operation and maintenance cost

The operation cost $C_{O}^{S S}$ includes charging $\operatorname{cost} C_{O_{-} \text {char }}^{S S}$, electric devices consumption cost $C_{O_{-} \text {power }}^{S S}$ and human service cost $C_{O_{-} \text {hs }}^{S S}$. Discharging cost $C_{O_{-} \text {dis }}^{S S}$ is considered as a benefit (or negative cost).

The maintenance cost $C_{M}^{S S}$ includes transformer maintenance cost $C_{M_{-} \mathrm{T}}^{S S}$, feeder maintenance $\operatorname{cost} C_{M_{-} \mathrm{F}}^{S S}$, charger maintenance cost $C_{M_{-} \mathrm{C}}^{S S}$ and other equipment maintenance cost $C_{M_{-} \text {oe }}^{S S}$, such that,

$C_{O_{-} i \mathrm{char}}^{S S}-C_{O_{-} i \mathrm{dis}}^{S S}+C_{O_{-} \text {ipower }}^{S S}+C_{O_{-} i \mathrm{hs}}^{S S}=C_{O_{-} i}^{S S} \leq C_{O_{-} i \max }^{S S}$

$C_{M_{-} i \mathrm{~T}}^{S S}+C_{M_{-} i \mathrm{~F}}^{S S}+C_{M_{-} i \mathrm{C}}^{S S}+C_{M_{-} i \mathrm{oe}}^{S S}=C_{M_{-} i}^{S S} \leq C_{M_{-} i \max }^{S S}$

where $C_{O_{-} i \max }^{S S}$ is the maximum operation limit of the $i$ th $\mathrm{EV}$ station; $C_{M_{-} i \max }^{S S}$ is the maximum maintenance limit of the 
$i$ th EV station.

By considering the above three factors, the EV power demand, necessary infrastructure and cost constraints are determined for optimal siting and sizing.

\subsection{Step III: Optimal siting and sizing}

In optimal siting and sizing, total cost minimization is usually considered as the optimization object. Other objects, such as load loss, RES support and environmental protection could be integrated to achieve multi-object optimization. For simplicity, the objective function is defined as follows,

$\min z=\sum_{i}^{N^{S S}}\left(C_{I_{-} i}^{S S}+C_{O_{-} i}^{S S}+C_{M_{-} i}^{S S}\right)$

$C_{I_{-} i}^{S S}, C_{O_{-} i}^{S S}$, and $C_{M_{-} i}^{S S}$ are calculated as the product of cost per unit power and actual charging/discharging power. Thus, the constraints for (29) are (22)-(28).

\section{Steady-state stability analysis}

Steady-state stability is a special case of small-signal stability. Steady-state stability is usually described by power steady-state stability reserve and voltage steady-state stability reserve. In practice, it is used in power system planning to determine limits for transmission power in steady-state (minutes to days). With EV integration, steady-state stability is used to limit the maximum EV charging and discharging power. Thus, in this paper, steady-state stability is included by calculation in hours rather than seconds.

Power steady-state stability reserve $K_{P}$ is set for power-angle steady-state stability and voltage steady-state stability reserve $K_{U}$ is set for voltage steady-state stability. $K_{P}$ is normally used in single-machine infinite-bus system and $K_{U}$ is normally used in single-load infinite-bus system,

$K_{P}=\frac{P_{\max }-P_{0}}{P_{0}} \times 100 \%$

$K_{U}=\frac{U_{0}-U_{c r}}{U_{0}} \times 100 \%$

where $P_{0}$ and $U_{0}$ are the actual operating power and voltage; $P_{\max }$ is the maximum power of steady-state stability; and $U_{c r}$ is the critical voltage of load buses. At normal operation, $K_{P}$ should be $>15-20 \%$ and $K_{U}$ should be $>10-15 \%$ [38].

\section{Case studies}

Four case studies have been use to demonstrate the issues in Section 3 to 6 . The cases are organized as follow:

Case A: Application of the proposed capacity forecasting model to load levelling (using predicted UK 2020 summer demand);

Case B: Application of the proposed capacity forecasting model for RES support in an example micro-grid;

Case C: EV station siting and sizing in a moderately-sized urban city center, (Belfast, NI);

Case D: Steady-state stability analysis in a small urban city (Lisburn, NI).

\subsection{Case A: Load levelling}

\subsubsection{Parameters}

Parameters for this case study are provided in Table 2 [2, 10, 32, 33]. The UK 2020 national summer daily load profile is shown in Fig. 2, with the consideration of the historical data [39] and energy efficiency improvement [40]. The gross demand excludes EVs but includes embedded solar and wind energy.

\subsubsection{Results and discussion}

The optimization function used here is (15). In 2020, since the total amount of EVs is considered a constant, EV penetration is not considered in the case study. Mode 1 in [31] is applied as the charging and discharging level in the simulation. Three scenarios are set in Table 3. The results are shown in Fig. 2.

In Fig. 1, the peak-valley difference decreases from $12389 \mathrm{MW}$ to $10219 \mathrm{MW}, 7664 \mathrm{MW}$, and 4658MW in scenario 1, 2, and 3, respectively. From Fig. 2 it is determined that a larger flexible EV proportion provides greater effectiveness in load levelling, since the charging-only EV demand can be regarded as a smooth base load, and EVs charge regularly with a periodic variation over $C T_{p}$. It is apparent that a higher EV penetration rate could render a better optimization result closer to the average demand in Fig. 2.

In previous studies [10], [15], there will be an obvious drop in the optimized results at around 7:00 or 8:00. This is because the charging process is continuous and it is not long enough to cover the full valley duration, which may aggravates the UK's "Economic 7". However, such drops are avoided by the inclusion of the flexible model with continuous and alternate charging and discharging.

In this case, EV discharging and charging results in peak-shaving and valley-filling, demonstrating the proposed model a feasible and effective solution in steady-state analysis with large-scale EV integration.

\subsection{Case B: RES support}

\subsubsection{Parameters}

The example micro-grid used in this case is shown in Fig. 3. The micro-grid is connected to the external system at the distribution level. There are four load terminals in this grid as well as wind energy, PV solar energy and gas turbines. 300 flexible BEVs are proposed to be integrated on this grid. The EV connection node is set as Bus 7 with another 1.5 MVA wind energy installed. Parameters of this micro-grid are available in [41]. The wind generation and PV solar generation 
profile and actual load profile are shown in Fig. 4.

\subsubsection{Results and discussion without transmission losses}

The optimization function used in this case is (16) when transmission losses are neglected. EV charging and discharging power levels are selected as Mode 1 in [31]. The simulation results are shown in Fig. 5.

In Fig. 5, negative power means that RES power is abundant and thus, the prime task of RES support is to eliminate such negative numbers. Afterwards, based on (16), an optimized load profile is obtained with less fluctuation in power demand. Thus, the proposed EV capacity forecasting model is also considered feasible for RES support.

Moreover, with EV charging and discharging, a better load profile is achieved and the rate-of-change of the net load (load with RES in Fig. 5) is improved meaning that any generation rate-of-change parameters, from gas turbines, for example, would not be as stringent if EVs were adopted.

\subsubsection{Results and discussion with transmission losses}

In terms of transmission losses and system configuration, the optimization function is shown in (16) and (21). The expression of parameters in the objective function in (21) is detailed in the Appendix. EV charging and discharging power levels are selected as Mode 1 in [31]. The simulation results are shown in Fig. 6.

In comparison between Fig. 5 and 6, it is apparent that there is no negative value in the "load with RES" curve in Fig. 6. This is because with the inclusion of transmission losses, the actual demand contribution from RES is reduced. However, compared to the original load curve, both the peak-valley difference and rate-of-change of the net load are decreased. The average transmission loss in this case is approximately $6.7 \%$.

\subsection{Case C: EV station Siting and Sizing}

\subsubsection{Parameters}

The City of Belfast is the capital of NI Almost one third of the total population in NI lives within the Belfast metropolitan area. Based on the population and total EV numbers in the UK, it is assumed that 11,000 BEVs and 3,200 PHEVs participate in the siting and sizing simulation of the Belfast city center area in this case. The network configuration is shown in Fig. 7. Due to security reasons, the parameters of the network are not given. The costs per unit power are shown in Table $4[20,42]$.

\subsubsection{Siting and sizing procedure}

In terms of geographical and electrical connection data, Bus D3, D4 and D5 are in the commercial center of Belfast, where there are a great deal of offices, shops and other work places, also surrounded by many business and commercial parking lots. The total peak load in this area is estimated as 114.6 MW and 23.3 MVar in the winter of 2020, with 20 ground car parks assumed (100-400 parking spaces) and 5 multi-story car parks (600-800 parking spaces) within 500 meters radius from the city center. Thus, all of these three nodes are candidate connection nodes for an EV station.

When all EVs are charging or discharging at the same time, at $3.5 \mathrm{~kW}$ [31] and $7 \mathrm{~kW}$ [32] levels, the total power is determined as approximately $50 \mathrm{MW}$ and $100 \mathrm{MW}$, respectively. Thus, candidate locations and capacities of EV stations are listed in Table 5. Numbers of candidate capacity refer to different sizes of EV stations. Such sizes are determined by load power and transformer rated power [20].

In power demand estimation, only flexible EVs are considered. The scheduled charging and discharging strategy is considered for load levelling. The available time duration is set from 6:00 am to 8:00 pm.

\subsubsection{Results and discussion}

The maximum charging demand occurs at 8:00 pm, which is $21.81 \mathrm{MW}$ at $3.5 \mathrm{~kW}$ level or $43.60 \mathrm{MW}$ at $7 \mathrm{~kW}$ level. Thus, EV station size is selected to be 30 or 50 MVA. The results are shown in Table 6 and 7.

The majority of EV station costs derive from land prices. In this calculation, about 160000 square meters [43] is required for total land cost. However, based on current car park status in Belfast city center (2015), most of this amount has been achieved. Thus, when land price is omitted, there is a significant reduction in total cost, which is almost £10 million pounds (sterling). From Table 7 it can be seen that there is overload risk at Line 3 when EV station is connected to Bus D3 or D4.

Therefore, it can be concluded from this case that the optimal site of an EV station is on Bus D5 with an optimal size of 50 MVA. At present, such an EV station could sufficiently supply charging and/or discharging services for EVs at different standard power levels in Belfast city center. Moreover, no additional new transformer or feeder would be required to be constructed at the distribution level. The total cost of this EV station would therefore be projected as $£ 12.5$ million pounds sterling (or 3.2 million pounds sterling excluding land cost, transformer cost, and feeder cost). Evidently, greater number of EVs would challenge these assertions and require further study.

\subsection{Case D: Steady-state Stability}

\subsubsection{Parameters}

Lisburn is the third largest city in NI which is 9 miles from Belfast city center. Many residents in Lisburn travel to Belfast during on Monday-Friday workdays, making this city a useful example to study large-scale EV usage and integration.

Based on the same assumptions mentioned in Section 7.3.1, it is supposed that there will be 2280 BEVs and 660 PHEVs in Lisburn in 2020. The charging and discharging power levels are set as $7 \mathrm{~kW}$ for standard charging and $50 \mathrm{~kW}$ for rapid charging [26]. The network configuration is shown in Fig. 8.

\subsubsection{Lisburn network description}

Because there is only one $33 \mathrm{kV}$ bus in this area (and currently no storage or large-scale RES), EV siting and sizing and RES support are neglected.

Based on the discussion in Section 3, scheduled EV charging/discharging strategies will result in different charging and discharging levels at different time intervals. Thus, charging and discharging levels at each time interval is always lower than the total charging and discharging requirement. In steady-state stability analysis, only the worst condition is required to 
identify the steady-state stability margin. The Lisburn area is a typical single-load infinite-bus system. Thus, only $K_{U}$ index is calculated.

Since it is assumed that most EVs travel to Belfast during daytime and come back to Lisburn late afternoon, it is impractical that all EVs charge at a fast charging level. However, this scenario is set as the least likely condition as an example.

\subsubsection{Results and discussion}

The total charging power at $7 \mathrm{~kW}$ and $50 \mathrm{~kW}$ in Lisburn are $20.58 \mathrm{MW}$ and $147 \mathrm{MW}$, respectively. The simulation results are shown in Table 8 .

From Table 8 it is apparent that the voltage steady-state stability reserve $K_{U}$ remains constant. This is because in EV integration, the relevant reactive power compensation devices are also installed locally [23], meaning that transferred active power is greater while transferred reactive power remains almost the same or perhaps lower. The corresponding buses can therefore be recognized as a PV node, rather than a PQ node in the power flow calculation. Although the voltage angles at Bus L1 and L2 increase, the reduction rates are very small. Thus, the Q-U characteristics are similar and the critical voltages of load buses $U_{c r}$ are the same.

In a winter-max scenario, the transformer load rates are much higher than summer-max scenario due to heavier winter heat load. In a fast charging scenario, the transformer load rate is $>50 \%$. Based on the network structure, if one transformer is tripped off during contingency, the other will be overloaded, rendering operational risk. However, one practical solution would include new construction or expansion of network assets to support excessive loading.

From the above results it is clear that by 2020 , the Lisburn local network has adequate steady-state stability to support the predicted $2280 \mathrm{BEVs}$ and 660 PHEVs. No voltage steady-state stability risks are determined and transformer loading is fair, with the exception that a rapid charging scenario may pose risks to operational security.

\section{Conclusions}

This paper has considered steady-state issues for emergent power systems with large-scale EV integration. A problem description highlighting several technical constraints is initially summarized. Thereafter, an EV capacity forecasting model has been developed, with respect to nine specified uncertainties. Based on the treatise in this paper, the proposed model can be used in specific applications, such as load levelling and RES support. The complexity of the model can be simplified to a quadratic programming problem. The work established in the paper has enabled an accurate profile for EV non-continuous or alternate charging and discharging to be obtained. A three-step EV station siting and sizing approach with respect to six factors has also been proposed. Thus, both an EV charging/discharging profile and station connection nodes have been identified, with consideration of stochastic and intermittent behavior in time, location and magnitude. The time-domain EV power profile and station connection nodes have therefore described EV component contribution (in the power flow solution) on power systems with large-scale (EV) integration. This includes steady-state analysis and initial values of stability analysis, both of which provide critical information for EV charging and potential impacts of large-scale connection. Moreover, using the specified power flow solution, indices to evaluate steady-state stability have been determined, which importantly decouples the stochastic and intermittent behavior of EVs from the energy system to provide a demand-response framework for management of EV assets.

The paper has included several case studies with particular applications to load levelling and RES support. The results provide evidence of the feasibility of the proposed model in the context presented. EV station siting and sizing has been determined in a typical urban city model to obtain optimal station location. The calculation of steady-state stability has been evaluated using the small-scale city model with results which indicate no risk to voltage steady-state stability but which importantly highlight other issues in terms of network assets, in particular transformer loading.

This work is particularly relevant to pertinent and potential problems which define the power system steady-state and dynamic stability in the emerging global context of greater EV connection and integration and in areas which have not yet been clearly defined, either by the broader academic community or by international policy, power system network standards bodies or EV manufacturers.

\section{Acknowledgments}

The authors would like to acknowledge the support of the EPSRC UK-China joint research consortium (EP/F061242/1), the Science Bridge Award (EP/G042594/1), Chinese Scholarship Council and Queen's University Belfast, UK. The authors also gratefully acknowledge Dr Paul Brogan from Queen's University Belfast for providing the data.

\section{Appendix}

For simplicity, resistances of the transformers are neglected and the generator buses and EV bus are considered as PV buses. Thus, the line currents of the micro-grid can be obtained as follows:

$$
\begin{aligned}
& I_{67}=\frac{P_{R E S 1}}{U_{3}}-\frac{P_{L 2}}{U_{6}}=\frac{U_{6}-U_{7}}{R_{67}} \\
& I_{89}=-\frac{P_{R E S 2}}{U_{2}} \\
& I_{78}=I_{67}-I_{89}-\frac{P_{L 3}}{U_{7}}-\frac{P_{E V}}{U_{7}}-\frac{P_{L 4}}{U_{8}}+\frac{P_{G}}{U_{4}}=\frac{U_{7}-U_{8}}{R_{78}}
\end{aligned}
$$

In (A1)-(A3), $U_{6}$ and $U_{8}$ are the unknown variables which can be calculated by (A1) and (A3), respectively. Therefore, all currents and resistances for the calculation of transmission losses can be achieved. 


\section{Reference}

[1] Zhou B, Littler T, Foley A. Electric Vehicle Capacity Forecasting Model with Application to Load Levelling. In: IEEE PES General Meeting 2015; 2015. p. 1-5.

[2] Department of Energy \& Climate Change. Renewable Energy Roadmap UK Update 2013; $2013 . \quad$ Available: <https://www.gov.uk/government/uploads/system/uploads/attachment_data/file/255182/UK_Renewable_Energy_Roadmap_-_5_November_-_FINA L_DOCUMENT_FOR_PUBLICATIO_.pdf> [Accessed: 22/06/15]

[3] JJ Grainger, WD Stevenson Jr. Power System Analysis. New York: McGraw Hill, 1994.

[4] Liu C, Chau KT, Wu D, et al. Opportunities and Challenges of Vehicle-to-Home, Vehicle-to-Vehicle, and Vehicle-to-Grid Technologies. Proc IEEE 2013; 101(11): 2409-2427.

[5] Shaaban MF, Atwa YM, El-Saadany EF. PEVs modeling and impacts mitigation in distribution networks. IEEE Trans Power Syst 2013; 28(2): $1122-1131$.

[6] Liu H, Hu Z, Song Y, et al. Decentralized Vehicle-to-Grid Control for Primary Frequency Regulation Considering Charging Demands. IEEE Trans Power Syst 2013; 28(3): 3480-3489.

[7] Rolink J, Rehtanz C. Large-Scale Modeling of Grid-Connected Electric Vehicles. IEEE Trans Power Del 2013; 28(2): 894-902.

[8] Yao W, Zhao J, Wen F, et al. A Hierarchical Decomposition Approach for Coordinated Dispatch of Plug-in Electric Vehicles. IEEE Trans Power Syst 2013; 28(3): 2768-2778

[9] Karfopoulos EL, Hatziargyriou ND. A Multi-Agent System for Controlled Charging of a Large Population of Electric Vehicles. IEEE Trans Power Syst 2013; 28(2): 1196-1204

[10] Papadopoulos P, Skarvelis-Kazakos S, Grau I, et al. Electric vehicles' impact on British distribution networks. IET Electr Syst Transp 2012; 2(3): 91-102.

[11] Shi L, Zhang Q, Pu Y. The reserve trading model considering V2G Reverse. Energy 2013; 59: 50-55.

[12] Luo Z, Hu Z, Song Y, et al. Optimal Coordination of Plug-In Electric Vehicles in Power Grids With Cost-Benefit Analysis-Part I: Enabling Techniques. IEEE Trans Power Syst 2013; 28(4): 3546-3555.

[13] Zhang P, Qian K, Zhou C, et al. A methodology for optimization of power systems demand due to electric vehicle charging load. IEEE Trans Power Syst 2012; 27(3): 1628-1636.

[14] Madzharov D, Delarue E, D’haeseleer W. Integrating electric vehicles as flexible load in unit commitment modeling. Energy 2014; 65: $285-294$.

[15] Zhang Q, Mclellan BC, Tezuka, T, et al. A methodology for economic and environmental analysis of electric vehicles with different operational conditions. Energy 2013; 61: 118-127.

[16] Bellekom S, Benders R, Pelgröm S, et al. Electric cars and wind energy: Two problems, one solution? A study to combine wind energy and electric cars in 2020 in The Netherlands. Energy 2012; 45: 859-866.

[17] Wang Z, Wang S. Grid Power Peak Shaving and Valley Filling Using Vehicle-to-Grid Systems. IEEE Trans Power Del 2013; 28(3): 1822-1829.

[18] Cai H, Du W, Yu XP, et al. Day-ahead Optimal Charging/Discharging Scheduling for Electric Vehicles in Micro-Grids. In: IET Renewable Power Generation Conference 2013; 2013. p. 1-4.

[19] Labeye E, Adrian J, Hugot M, et al. Daily use of an electric vehicle: bahavioural changes and potential for ITS support. IET Intell Transp Syst 2013; 7(2): 210-214.

[20] Liu Z, Wen F, Ledwich G. Optimal planning of electric-vehicle charging station in distribution systems. IEEE Trans Power Del 2013; 28(1): $102-110$.

[21] Moradijoz M, Moghaddam MP, Haghifam MR, et al. A multi-objective optimization problem for allocating parking lots in a distribution network. Int J Electr Power Energy Syst 2013; 46: 115-122.

[22] Jia L, Hu Z, Song Y, et al. Optimal siting and sizing of electric vehicle charging station. In: IEEE International Electric Vehicle Conference (IEVC) 2012; 2012. p.1-6.

[23] Crosier R, Wang S. DQ-Frame Modeling of an Active Power Filter Integrated With a Grid-Connected, Multifunctional Electric Vehicle Charging Station. IEEE Trans Power Electron 2013; 28(12): 5702-5716.

[24] Neaimeh M, Wardle R, Jenkins AM, et al. A probabilistic approach to combining smart meter and electric vehicle charging data to investigate distribution network impacts. Appl Energy 2015; in press.

[25] Battery University. BU-1204: Batteries for Electric Cars; 2015. Available: 〈http://batteryuniversity.com/learn/article/batteries_for_electric_cars> [Accessed: 22/06/15]

[26] GWL/Power <http//files.ev-power_eu/inc/_doc/attach/StoItem/3148/GWL-WINA_WN10AH_Specifications.pdf> [Accessed:22/06/15]

[27] Landi M, Gross G. Measurement Techniques for Online Battery State of Health Estimation in Vehicle-to-Grid Applications. IEEE Trans Instrum Meas 2014; 63(5): 1224-1234

[28] Viswanathan VV, Kintner-Meyer M. Second Use of Transportation Batteries: Maximizing the Value of Batteries for Transportation and Grid Services. IEEE Trans Veh Technol 2011; 60(7): 2963-2970.

[29] The European Association for Advanced Rechargeable Batteries. E-mobility Roadmap for the EU battery industry; 2015. Available: <http://www.rechargebatteries.org/wp-content/uploads/2013/04/Battery-Roadmap-RECHARGE-05-July-2013.pdf> [Accessed: 22/06/15]

[30] Boulanger AG, Chu AC, Maxx S, et al. Vehicle electrification: Status and issues. Proc IEEE 2011; 99(6): 1116-1138.

[31] IEC Standard. Electric Vehicle Conductive Charging System - Part 1: General Requirements, IEC 61851-1; 2010.

[32] IEC Standard. Plugs, socket-outlets, vehicle connectors and vehicle inlets - Conductive charging of electric vehicles - Part 2: Dimensional compatibility and interchangeability requirements for a.c. pin and contact-tube accessories, IEC 62196-2; 2011

[33] Department for Transport. National Travel Survey 2012; 2013. Available: 〈https://www.gov.uk/government/publications/national-travel-survey-2012> [Accessed: 22/06/15]

[34] Yang Z, Li K, Foley A, et al. Optimal scheduling methods to integrate plug-in electric vehicles with the power system: a review. In: 19th World Congress of the International Federation of Automatic Control. IFAC, 2014; 2014. p. 8594-8603.

[35] Clement-Nyns K, Haesen E, Driesen J. The Impact of Charging Plug-In Hybrid Electric Vehicles on a Residential Distribution Grid. IEEE Trans Power Syst 2010; 25(1): 371-380.

[36] Das S, Suganthan PN. Differential Evolution: A survey of the State-of-the-Art. IEEE Trans Evol Comput 2011; 15(1): 4-31.

[37] del Valle Y, Venayagamoorthy GK, Mohagheghi S, et al. Particle Swarm Optimization: Basic Concept, Variants and Applications in Power Systems. IEEE Trans Evol Comput 2008; 12(2): 171-195.

[38] Ni Y, Chen S, Zhang B. Dynamic Power System Theory and Analysis. Beijing: Tsinghua University Press, 2002.

[39] National Grid. $\quad$ Historical $\quad$ Demand Data; 2015 <https://www.ofgem.gov.uk/ofgem-publications/75232/electricity-capacity-assessment-report-2013.pdf> [Accessed: 22/06/15]

[41] Cai H. Enhancement of Power System Dynamic Stability using Electric Vehicles and Distributed Generation. PhD dissertation, Sch of Electron, Electr Eng \& Comput Sci, Queen's Univ Belfast, Belfast, UK, 2013.

[42] Better Generation. Selling your electricity to the grid; 2015.2 Available: <http://www.bettergeneration.co.uk/green-energy-factsheets/selling-your-electricity-to-the-grid.html> [Accessed: 22/06/15] 
Group, Department of Environment, Northern Ireland.

Parking standards;

2015. Available: <http://www.planningni.gov.uk/downloads/parking-standards.pdf> [Accessed: 22/06/15]

Figures and tables

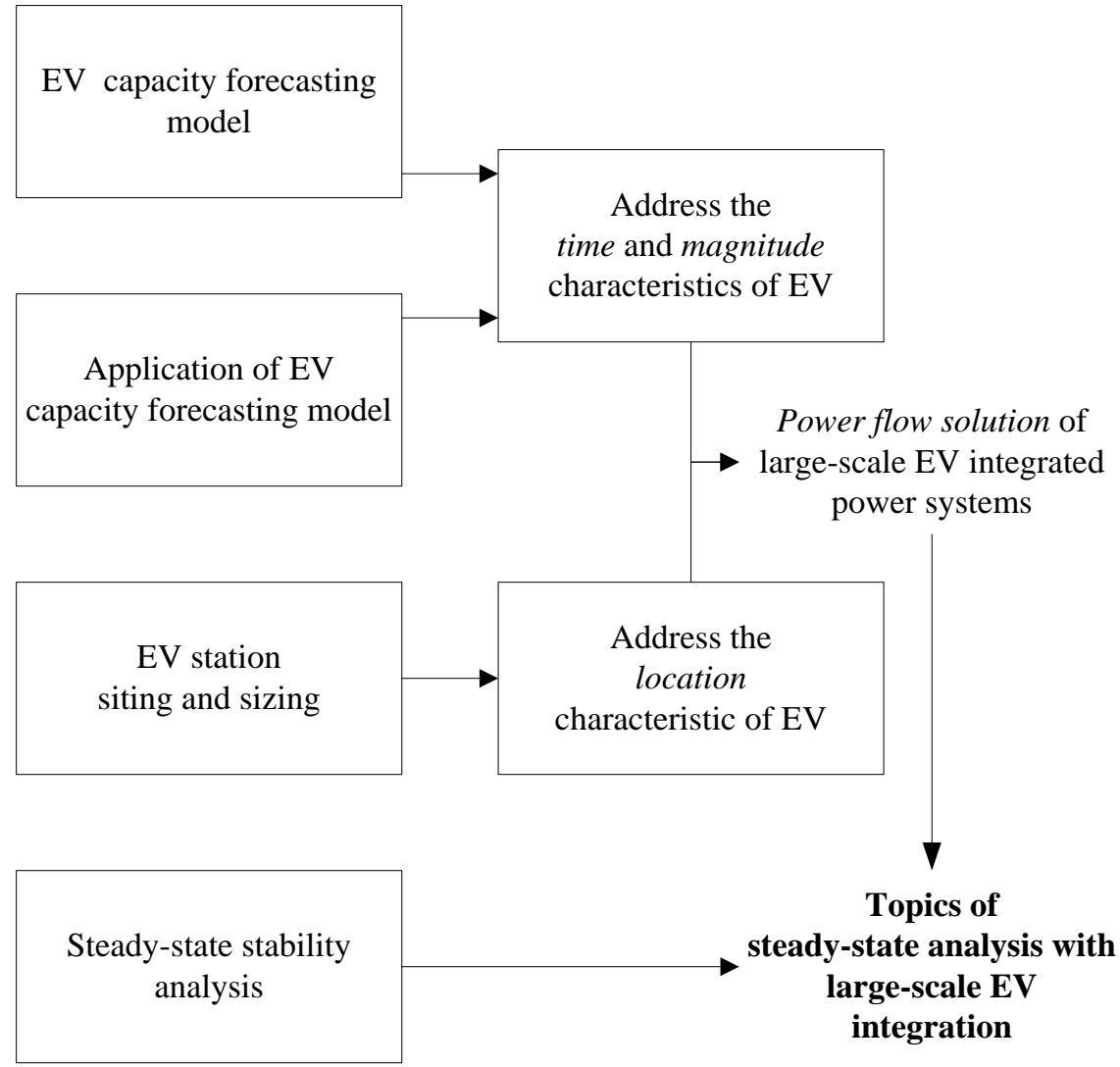

Fig. 1 Topics of steady-state analysis with large-scale EV integration

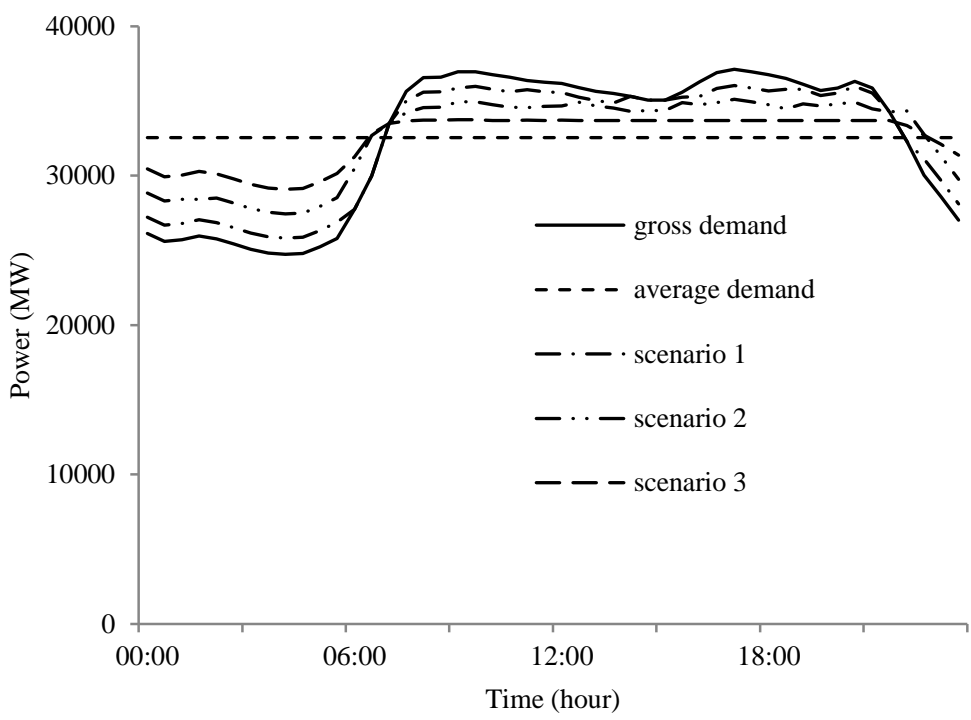

Fig. 2. Load levelling results 


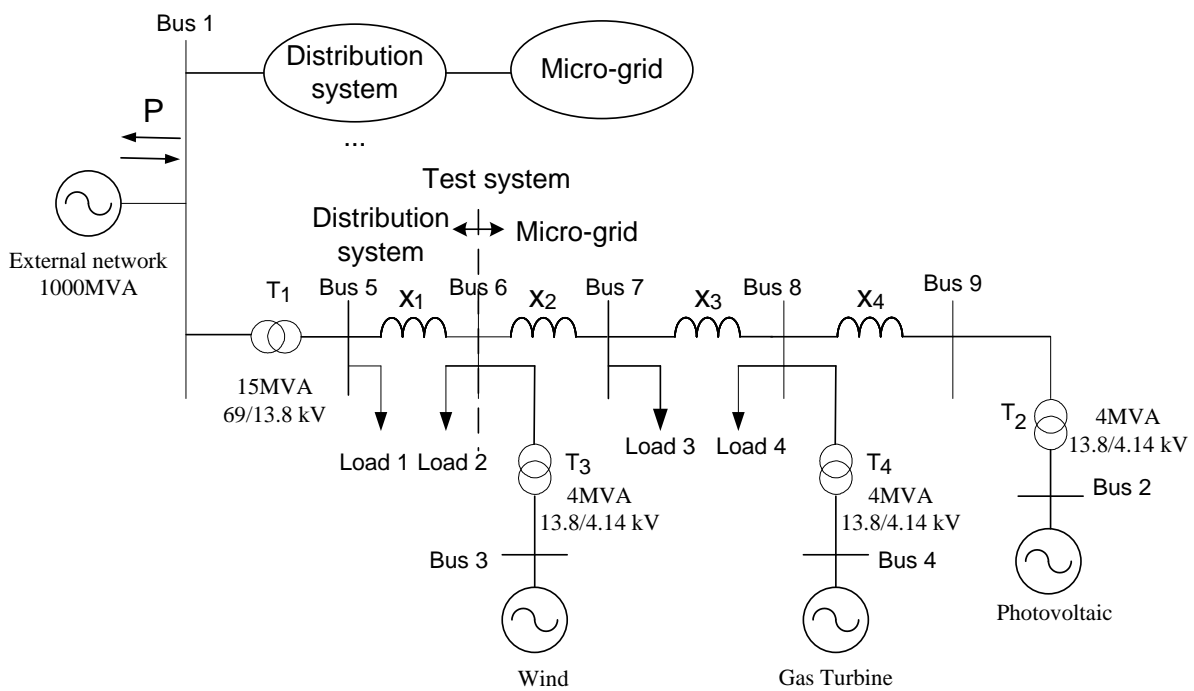

Fig. 3. Example micro-grid

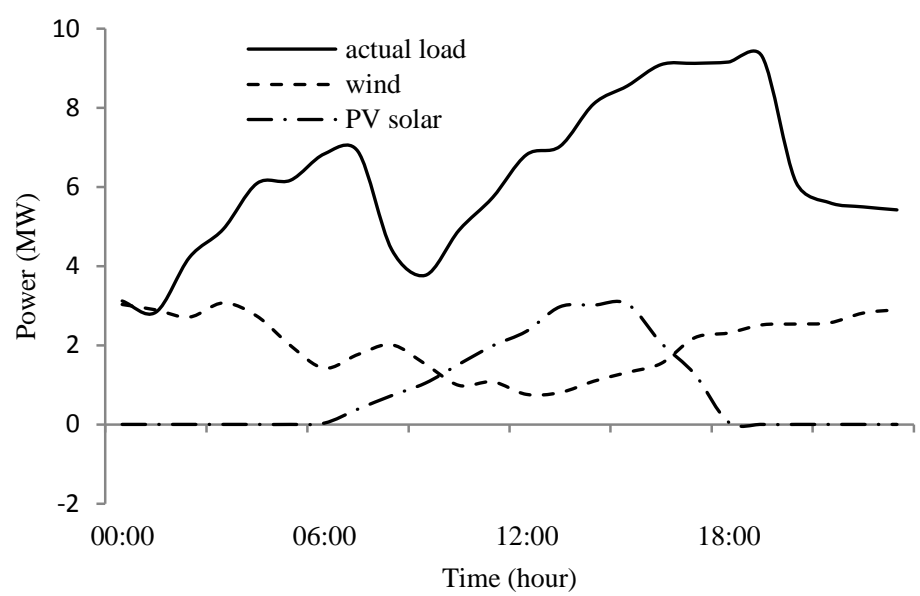

Fig. 4. Wind and PV solar generation profile

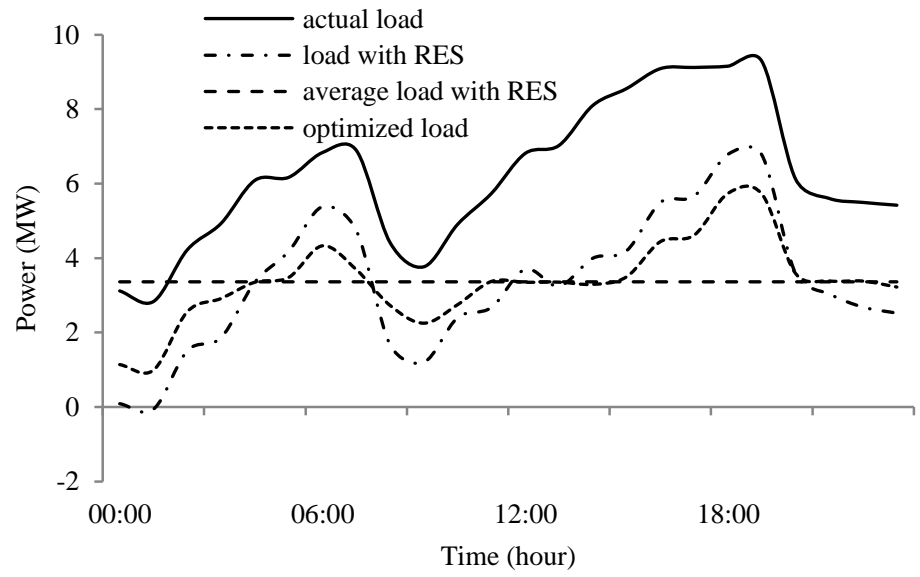

Fig. 5. RES support results without transmission losses 


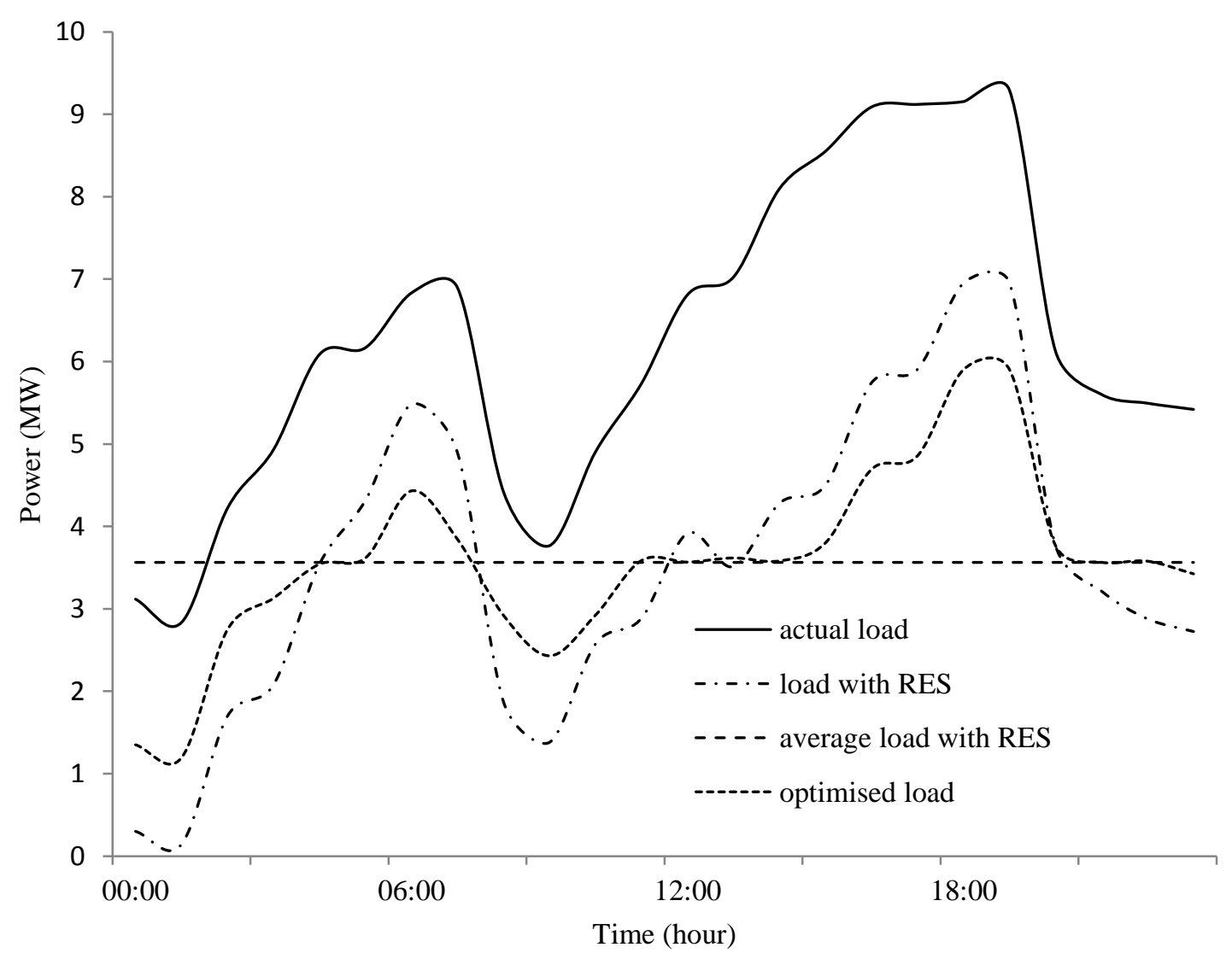

Fig. 6. RES support results with transmission losses

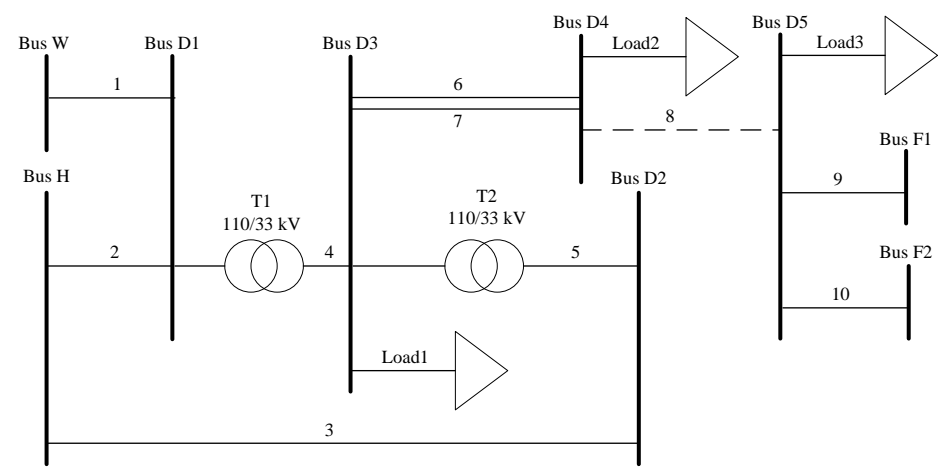

Fig. 7. The network configuation of Belfast city center area

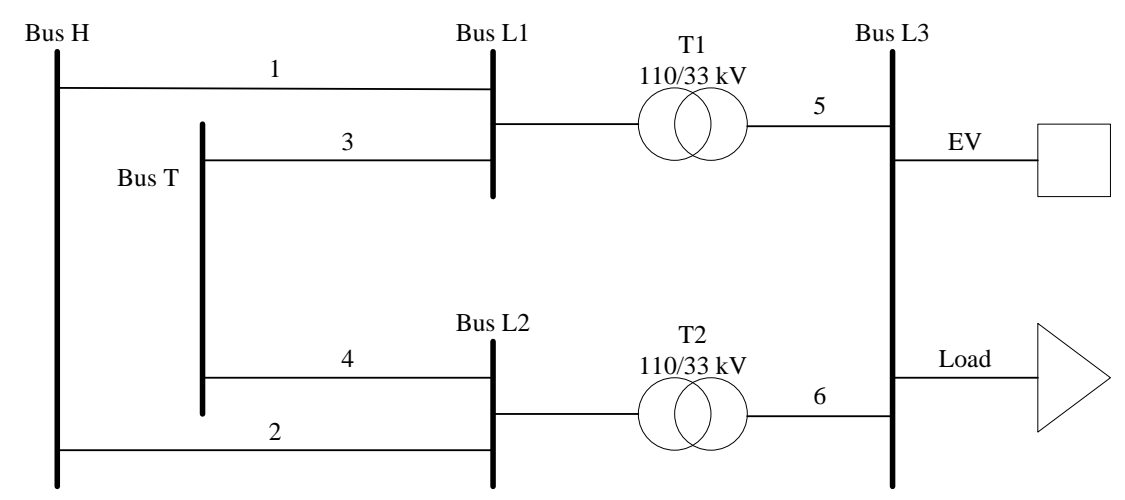

Fig. 8. The network configuation of Lisburn area

Table 1

Charging and discharging scenarios for flexible EVs

Time $k$

Time $l$

Charging

Charging 


\begin{tabular}{lll}
2 & Charging & Discharging \\
3 & Discharging & Charging \\
4 & Discharging & Discharging \\
\hline
\end{tabular}

Table 2

List of Parameters

\begin{tabular}{llll}
\hline Symbols & Values & Symbols & Values \\
\hline$N_{B}$ & 1.2 million & $N_{H}$ & 0.35 million \\
$P_{c}, P_{r d}$ & $7 \mathrm{~kW}$ & $T_{1}$ & $3.2^{\mathrm{a}}, 0.64^{\mathrm{b}}$ \\
$T_{2}$ & $4^{\mathrm{a}}, 0.8^{\mathrm{b}}$ & $T_{3}$ & $1.8^{\mathrm{a}}, 0.36^{\mathrm{b}}$ \\
$T_{a \text { min }}$ & 0 & $T_{a \text { max }}$ & 47 \\
$N_{d}$ & 48 & $\mu$ & 3.20 \\
$\sigma$ & 0.6528 & $E_{\text {end }}$ & 0.5 \\
$E_{c_{-} \text {set }}$ & 0.3 & $C T_{p}$ & 2.9 \\
\hline
\end{tabular}

a. For BEVs with $25 \mathrm{kWh}$ lithium-ion battery; b. For PHEVs with $5 \mathrm{kWh}$ lithium-ion battery

Table 3

Scenarios for load levelling

\begin{tabular}{ccc}
\hline & Proportion of charging only EVs & Proportion of flexible EVs \\
\hline 1 & $80 \%$ & $20 \%$ \\
2 & $50 \%$ & $50 \%$ \\
3 & $20 \%$ & $80 \%$ \\
\hline
\end{tabular}

Table 4

Costs per unit power

\begin{tabular}{|c|c|c|c|c|c|}
\hline Item & Cost & Unit & Item & Cost & Unit \\
\hline$C_{I_{-} \mathrm{lp}}^{S S}$ & 58.66 & $\mathrm{GBP} / \mathrm{m}^{2}$ & $C_{O_{-} \mathrm{hs}}^{S S}$ & 18 & $\mathrm{GBP} / \mathrm{h} / \mathrm{p}$ \\
\hline$C_{I_{-} \mathrm{C}}^{S S}$ & 21.29 & GBP/kVA & $C_{O_{-} \text {dis }}^{S S}$ & 0.08 & $\mathrm{GBP} / \mathrm{kWh}$ \\
\hline$C_{I_{-} \mathrm{T}}^{S S}$ & 25.05 & $\mathrm{GBP} / \mathrm{kVA}$ & $C_{M_{-} \mathrm{T}}^{S S}$ & 7.31 & $\mathrm{GBP} / \mathrm{kVA}$ \\
\hline$C_{I_{-} \mathrm{oe}}^{S S}$ & 18.98 & GBP/kVA & $C_{M_{-} \mathrm{F}}^{S S}$ & 6.39 & $\mathrm{GBP} / \mathrm{kVA}$ \\
\hline$C_{O_{-} \text {char }}^{S S}$ & 0.17 & GBP/kWh & $C_{M_{-} \mathrm{C}}^{S S}$ & 5.47 & GBP/kVA \\
\hline$C_{O_{-} \text {power }}^{S S}$ & 0.17 & GBP/kWh & $C_{M_{-} \text {oe }}^{S S}$ & 3.20 & GBP/kVA \\
\hline
\end{tabular}

Table 5

Candidate locations and capacities of EV stations

\begin{tabular}{cc}
\hline Candidate node & Candidate capacity/MVA \\
\hline 1 & $30,50,60,80,100$ \\
2 & $30,50,60,80,100$ \\
3 & $30,50,60,80,100$ \\
\hline
\end{tabular}

Table 6

Siting and sizing results

\begin{tabular}{cccc}
\hline Sites & Sizes/MVA & Cost/GBP & Cost without $C_{I_{-} \text {lp }}^{S S} / \mathrm{GBP}$ \\
\hline D3, D4, D5 & 30 & $12,040,411.08$ & $2,713,823.04$ \\
D3, D4, D5 & 50 & $13,794,211.08$ & $4,467,623.04$ \\
\hline
\end{tabular}

Table 7

Maximum load rate and its location

\begin{tabular}{|c|c|c|c|c|c|}
\hline Sizes/MVA & Sites & $\mathrm{T} 2$ & Line 3 & Line 6/7 & Line 9 \\
\hline \multirow{3}{*}{30} & D3 & $26.99 \%$ & $50.03 \%$ & - & - \\
\hline & D4 & $26.99 \%$ & $50.03 \%$ & $10.27 \%$ & - \\
\hline & D5 & - & - & - & $25.61 \%$ \\
\hline \multirow{3}{*}{50} & D3 & $34.16 \%$ & $57.20 \%$ & - & - \\
\hline & D4 & $34.16 \%$ & $57.20 \%$ & $17.44 \%$ & - \\
\hline & D5 & - & - & - & $32.78 \%$ \\
\hline
\end{tabular}

Table 8

Simulation results

\begin{tabular}{|c|c|c|}
\hline & Summer-max & Winter-max \\
\hline$K_{U}$ without EV & $47.8 \%$ & $47.8 \%$ \\
\hline $\begin{array}{c}\text { Transformer load rate } \\
\text { without EV }\end{array}$ & $28.2 \%$ & $36.6 \%$ \\
\hline
\end{tabular}




$\begin{array}{ccc}K_{U} \text { under standard charging } & 47.8 \% & 47.8 \% \\ \text { Transformer load rate } & 35.5 \% & 43.3 \% \\ \text { under standard charging } & 47.8 \% & 47.8 \% \\ K_{U} \text { under rapid charging } & 56.7 \% & 61.9 \% \\ \quad \begin{array}{l}\text { Transformer load rate } \\ \text { under rapid charging }\end{array} & & \end{array}$

